\title{
RETRACTED ARTICLE: A novel CDMA protocol for hierarchical wireless emergency communication networks in multimedia context
}

\author{
Hongtao Gao ${ }^{1}$
}

Received: 15 October 2017 /Revised: 26 October 201 Accepted: 30 October 2017 /

Published online: 9 November 2017

(C) Springer Science+Business Media, LLC, part of Springer Nature 2017

The Editor-in-Chief has retracted this article [1], which was published as part of special issue "Multi-source Weak Data Management using Big Data", because the article shows substantial overlap most notably with the article cited [2]. In addition, there is evidence of figure duplication without appropriate permission, as well as evidence suggesting an attempt to subvert the peer review process.

Author Hongtao Gao agrees to this retraction.

\section{References}

1. Gao, H. A novel CDMA protocol for hierarchical wireless emergency communication networks in multimedia context. Multimed Tools Appl (2017). https://doi.org/10.1007 /s11042-017-5377-3

2. Du, C.B., Quan, H.D., Cui, P.Z. et al. Carrier sense random packet CDMA protocol in dual-channel networks. Radioengineering (2015). https://oi.org/10.13164/re.2015.0507

Electronic supplementary material The online version of this article (https://doi.org/10.1007/s11042-0175377-3) contains supplementary material, which is available to authorized users.

\section{Hongtao Gao}

gaohongtao@126.com

1 Department of Cyber Crime Investigation, Criminal Investigation Police University of China, Hangzhou, China 